УДК 621.396.1

${ }^{1}$ Сергій Валентинович Ковбасюк (ооктор технічних наук, с.н.с.)

${ }^{2}$ Фелікс Михайлович Андрєєв (доктор технічних наук, професор)

${ }^{3}$ Андрій Віталійович Статкус (кандидат технічних наук, доцент)

${ }^{1}$ Житомирський військовий інститут ім. С. П. Корольова, Житомир, Украйна

${ }^{2}$ Харківський Національний університет ім. В. Н. Каразіна, Харків, Украӥна

${ }^{3}$ Харківський Національний технічний університет, Харків, Украйна

\title{
ОЦІНКА МОЖЛИВОСТІ ПОКРАЩЕННЯ ТОЧНІСНИХ ПОКАЗНИКІВ АЛГОРИТМІВ УТОЧНЕННЯ КУТОВИХ ШВИДКОСТЕЙ БАЛІСТИЧНИХ І КОСМІЧНИХ ОБ'ЄКТІВ У РЛС НАДГОРИЗОНТНОГО ВИЯВЛЕННЯ
}

У попередніх роботах авторами розглянуті теоретичні можливості та практичні рекомендаціі підвищення точності визначення координат $i$ достовірності класифікації балістичних $i$ космічних об'єктів за рахунок визначення вищих похідних дальності до об'єкту спостереження в радіолокаційних станціях надгоризонтного виявлення. Але авторами не було розглянуто рекомендації шцодо практичного обрання варіанту побудови алгоритму уточнення кутових швидкостей, який забезпечує максимальну точність оцінювання координат цілі. Тому в статті розглянуто методику порівняльної оцінки точнісних характеристик алгоритмів уточнення кутових швидкостей балістичних і космічних об'єктів та очінка рівня їх покращення за рахунок використання різних варіантів побудови алгоритму уточнення вищих похідних дальності, включно з інформацією про третю похідну дальності. За результатами моделювання зроблено висновки про вибір найкращого варіанту алгоритму оброблення даних в залежності від обстановки і вихідних даних.

Ключові слова: радіолокаційні станиії надгоризонтного виявлення, балістичні і космічні об'єкти, алгоритм уточнення кутових швидкостей иілі

\section{Вступ}

Постановка проблеми. РЛС надгоризонтного виявлення (НГВ) балістичних та космічних об’єктів (БКО) типу 5Н86-М («Днепр»), крім великої дальності виявлення (кілька тисяч км), повинні забезпечувати достатньо високі точності вимірювання координат цих об'єктів. Для рішення цього завдання до їх складу додатково введено аналого-цифрові системи когерентної обробки (АЦСКО) пачечних сигналів, які забезпечують високоточні незалежні вимірювання радіальних швидкості $R^{(1)}$ та прискорення $R^{(2)}$ БКО [1]. В комплексному робочому алгоритмі РЛС існує спеціальний алгоритм уточнення вищих похідних дальності (АУВПД) [2]. У цьому алгоритмі для оцінки вектора радіальних параметрів БКО $\bar{R}_{y}^{(1)}$ на момент закінчення інтервалу супроводження $\bar{R}_{y}^{(1)}=\left(R_{y}^{(1)}, R_{У}^{(2)}, R_{y}^{(3)}, R_{y}^{(4)}\right)^{T}$ використовуються виміри (опорні точки(ОТ)) радіальних параметрів, що пройшли селекцію, шляхом об'єднання в траєкторію та згладжування. В роботі [3] встановлено, що параметри траєкторії БКО, які отримані покоординатним згладжуванням вимірювань, можна покращити. Для цього необхідно використати інформацію про радіальне прискорення БКО $\hat{R}_{y}^{(2)}$ та його дисперсії для уточнення кутових швидкостей БКО. В цій же роботі [3] відмічається, що степінь уточнення тим вище, чим більше абсолютне значення відповідної кутової швидкості та вище точність оцінювання $R_{y}^{(2)}$ за даними АУВПД. Тому, отримана на виході
АУВПД оцінка $\widehat{R}_{y}^{(2)}$ та піi дисперсія використовуються у подальшому в алгоритмі точної обробки (АТО), що входить до складу комплексного робочого алгоритму РЛС, для підвищення точності оцінювання кутових швидкостей БКО, отриманих в ході згладжування некогерентних вимірювань. Відомо, що точність вимірювання параметрів траєкторій балістичних i космічних орбіт об'єктів в першу чергу залежить від точності вимірювання кутових швидкостей БКО. Тому, актуальним $є$ завдання пошуку можливостей покращення точнісних характеристик алгоритмів уточнення кутових швидкостей БКО, які використовують для цього інформацію про їх радіальні прискорення.

Аналіз останніх досліджень і публікацій. У штатному режимі роботи РЛС вхідною інформацією АУВПД $\epsilon$ результати вимірювань $\widehat{R}^{(1)}$ в режимі супроводження БКО (це режим С8, коли БКО опромінюється когерентною пачкою 38 імпульсів) та результати трьох вимірювань $\widehat{R}^{(1)}$ i $\widehat{R}^{(2)}$ за даними режиму фазотраєкторного накопичення (ФТН-16), коли АЦСКО обробляє вже когерентну пачку з 16 імпульсів. В роботі [4] пропонується додатково використовувати на етапі супроводження БКО (режим С8, коли $N=8$ ) не тільки вимірювання $R^{(1)}$, але і вимірювання $R^{(2)}$ та формувати вектор когерентних вимірювань радіальних параметрів. В роботі [5] встановлено, що при $N=32$ АЦСКО може забезпечити необхідну для практики точність вимірювання третьої похідної дальності до цілі. Зроблено 
висновок про доцільність введення додаткового режиму ФТН-32, коли кількість імпульсів в пачці $N=32$, та розширення вектору когерентних вимірювань радіальних параметрів до трьохкомпонентного $\widehat{R}_{A Ц С К O-3}=\left(\widehat{R}^{(1)}, \widehat{R}^{(2)}, \widehat{R}^{(3)}\right)$, де $\widehat{R}^{(3)}$ - оцінка третьої похідної дальності до БКО. В роботі [6] показано, що, якщо у АУВПД для оцінки вектору $R_{y}^{(1)}$ використовуються додатково оцінки радіального прискорення $\hat{R}^{(2)}$ та третьої похідної дальності $\hat{R}^{(3)}$, то з'являються нові компромісно-оптимальні варіанти побудови АУВПД. Вони забезпечують максимальну для альтернативних варіантів точність оцінок $\widehat{R}^{(1)}$ и $\widehat{R}^{(2)}$. Коли завадо-цільова обстановка в зоні огляду РЛС дозволяє призначити по БКО три рази режим ФТН-32 замість режиму ФТН-16, це варіант $v=3$. Якщо обстановка ускладнюється, таким варіантом $\epsilon \quad v=6$, коли по БКО, крім режиму С8, призначається один режим ФТН-32 та два ФТН16. Коли завадо-цільова обстановка в зоні огляду РЛС складна, ніяке додатково до штатного виділення ресурсів циклу повільного огляду (ЦПО) неможливо i необхідно працювати на існуючому рівні енергетичних витрат (варіант $v=2$ ). Варіант $v=2$, на відміну від штатного режиму роботи при супроводженні цілі (тобто в режимі C8), використовує двокомпонентний вектор $\widehat{R}_{\text {АЦСКО-1/2 }}=\left(\widehat{R}^{(1)}, \widehat{R}^{(2)}\right)$. Наскільки з запропоновані варіанти побудови АУВПД дозволять підвищити точність вимірювання кутових швидкостей невідомо.

Метою статті $\epsilon$ розробка методики порівняльної оцінки точнісних характеристик алгоритмів уточнення кутових швидкостей балістичних і космічних об'єктів РЛС НГВ та оцінка ступеню їх покращення за рахунок використання різних варіантів побудови алгоритму уточнення вищих похідних дальності.

\section{Виклад основного матеріалу дослідження}

Методика порівняльної оцінки точнісних характеристик алгоритмів уточнення кутових швидкостей БКО. Вектори, сформовані з вектору поточної оцінки параметрів траєкторії цілі $R_{C}$ шляхом заміни оцінок похідних дальності даного вектора $\hat{R}_{C}^{(1)}, \hat{R}_{C}^{(2)}$ на $R_{y}^{(1)}, R_{y}^{(2)}$, які отримані 3 використанням результатів роботи АЦСКО, називаються векторами ФТН $R_{\Phi}$. Після цього в АТО виконується уточнення оцінок азимутальної $\varepsilon_{C}^{(1)}$ та кутомісної $\gamma_{C}^{(1)}$ швидкостей із складу вектору поточної обробки $R_{C}$ (або $\left.\vec{R}_{\Phi}\right)$. Працює алгоритм уточнення кутових швидкостей 3 використанням тільки уточнених оцінок $R_{y}^{(2)}$ та їх дисперсій, за допомогою яких формуються уточненні значення кутових швидкостей $\varepsilon_{y T}^{(1)}, \gamma_{y T}^{(1)}$. Вектори, сформовані з $R_{C}$ або $R_{\Phi}$ заміною оцінок кутових швидкостей $\varepsilon_{C}^{(1)}$ та $\gamma_{C}^{(1)}$ на $\varepsilon_{y T}^{(1)}, \gamma_{y T}^{(1)}$, називаються уточненими векторами $R_{\text {ут }}$. Формування уточненого вектору $R_{\text {УT }}$ (та кореляційної матриці похибок (КМП) $K_{\text {УT }}$ уточненої оцінки $R_{У T}$ ) здійснюється шляхом заміни оцінок кутових швидкостей $\varepsilon_{C}^{(1)}, \gamma_{C}^{(1)}$ у складі вектора $R_{C}$ (та його КМП $R_{C}$ ) на оцінки $\varepsilon_{y T}^{(1)}, \gamma_{\text {у }}^{(1)}$, що обчислюються за формулами [3]:

$\varepsilon_{y T}^{(1)}=\varepsilon_{C}^{(1)}\left\{1+4 m_{0}^{-1} R_{C} \cos ^{2} \gamma_{C} \sigma^{2}\left(\varepsilon_{C}^{(1)}\right)\left[R_{y}^{(2)}-R_{C}^{(2)}\right]\right\}^{1 / 2}$,

$\gamma_{y T}^{(1)}=\gamma_{C}^{(1)}\left\{1+4 m_{0}^{-1} R_{C} \sigma^{2}\left(\gamma_{C}^{(1)}\right)\left[R_{y}^{(2)}-R_{C}^{(2)}\right]\right\}^{1 / 2}$,

$\sigma^{2}\left(\varepsilon_{y T}^{(1)}\right)=\sigma^{2}\left(\varepsilon_{C}^{(1)}\right)\left\{1+\cos ^{4} \gamma_{C} \frac{4 R_{C}^{2}\left(\varepsilon_{C}^{(1)^{2}} p_{0} p_{2}\right)}{p_{1} p_{2}+4 R_{C}^{(2)}\left(\gamma_{C}^{(1)}\right)^{2} p_{0} p_{1}}\right\}^{-1}$,

$\sigma^{2}\left(y_{y T}^{(1)}\right)=\sigma^{2}\left(y_{C}^{(1)}\right)\left\{1+\frac{4 R_{C}^{2}\left(y_{C}^{(1)^{2}} p_{0} p_{1}\right)}{p_{1} p_{2}+4 R_{C}^{(2)}\left(\varepsilon_{C}^{(1)}\right)^{2} p_{0} p_{2} \cos ^{4} y_{C}}\right\}^{-1}$,

де: $R_{y}^{(2)}$ - оцінка радіального прискорення зі складу вектора $R_{y}$ за результатами АУВПД;

$\varepsilon_{y T}^{(1)}, y_{y T}^{(1)}-$ уточнені оцінки азимутальної та кутомісної швидкостей;

$\sigma^{2}\left(\varepsilon_{y T}^{(1)}\right), \sigma^{2}\left(\gamma_{y T}^{(1)}\right)-$ дисперсії цих уточнених оцінок.

У формулах (1)..(4) введені позначення:

$$
\begin{aligned}
& m_{0}= \sigma^{2}\left(R_{y}^{(2)}\right)+\left(\mu / R_{3}^{2}\right)^{2} \sigma^{2}\left(\gamma_{C}\right)+4 R_{C}^{2}\left(\gamma_{C}^{(1)}\right)^{2} \sigma^{2}\left[y_{C}^{(1)}\right]+ \\
&+4 R_{C}^{2}\left(\varepsilon_{C}^{(1)}\right)^{2} \sigma^{2}\left(\varepsilon_{C}^{(1)}\right) \cos ^{4} y_{C}, \\
& p_{0}=\left\{\sigma^{2}\left(R_{y}^{(2)}\right)+\left(\mu / R_{3}^{2}\right)^{2} \sigma^{2}\left(\gamma_{C}\right)\right\}^{-1}, \\
& p_{1}=\left\{\sigma^{2}\left(\varepsilon_{C}^{(1)}\right)+\sigma^{2}\left(\Delta \varepsilon^{(1)}\right)\right\}^{-1}, \\
& p_{2}=\left\{\sigma^{2}\left(\gamma_{C}^{(1)}\right)+\sigma^{2}\left(\Delta \gamma^{(1)}\right)\right\}^{-1},
\end{aligned}
$$

де: $\sigma^{2}\left(\Delta \varepsilon^{(1)}\right), \sigma^{2}\left(\Delta \gamma^{(1)}\right) \quad$ константи, які враховують можливі систематичні похибки $\Delta \varepsilon^{(1)}$ i $\Delta \gamma^{(1)}$ при оцінюванні $\varepsilon_{C}^{(1)}$ та $\gamma_{C}^{(1)}$, отримані шляхом згладжування вимірювань відповідних кутів;

$R_{3}$ радіус Землі.

Використовуючи наведені формули (1)..(8), проведемо оцінку кількісного впливу точності оцінювання $R_{y}^{(2)}$ на точність оцінок кутових швидкостей. Пропонована методика основана на співставленні точності уточнених оцінок кутових швидкостей при різній точності уточненої оцінки $R_{y}^{(2)}$. Вважаємо, що маємо дві оцінки $R_{y 1}^{(2)}$ та $R_{y 2}^{(2)}$, що характеризуються відповідно своїми дисперсіями $\sigma^{2}\left(R_{y 1}^{(2)}\right)$ та $\sigma^{2}\left(R_{y 2}^{(2)}\right)$, при чому для визначеності

$$
\sigma^{2}\left(R_{y 1}^{(2)}\right) / \sigma^{2}\left(R_{y 2}^{(2)}\right)=d>1
$$

Тоді, в результаті уточнення вектора $\vec{R}_{C}$ цими оцінками отримаємо дві пари оцінок кутових швидкостей БКО $\varepsilon_{y T 1}^{(1)}, \gamma_{y T 1}^{(1)}$ та $\varepsilon_{y T 2}^{(1)}, \gamma_{y T 2}^{(1)}$, які характеризуються своїми дисперсіями $\sigma^{2}\left(\varepsilon_{\text {УT1 }}^{(1)}\right), \sigma^{2}\left(\gamma_{\text {עT1 }}^{(1)}\right)$ і $\sigma^{2}\left(\varepsilon_{\text {УT2 } 2}^{(1)}\right), \sigma^{2}\left(\gamma_{\text {УT } 2}^{(1)}\right)$. Вплив точності оцінки $R_{y}^{(2)}$ на точність оцінки кутових 
швидкостей характеризуємо відношенням

$$
K\left\lfloor\alpha_{y T}^{(1)}\right\rfloor=\sigma^{2}\left\lfloor\alpha_{y T 1}^{(1)}\right\rfloor / \sigma^{2}\left\lfloor\alpha_{y T 2}^{(1)}\right\rfloor,
$$

де $\alpha_{y T}^{(1)} \in\left(\varepsilon_{y T}^{(1)}, \gamma_{y T}^{(1)}\right)$.

Введемо позначення для параметра прольоту

$$
A=4 R_{C}^{2}\left[\varepsilon_{C}^{(1)}\right]^{2} \cos ^{4} \gamma_{C}
$$

і параметру атаки БКО

$$
B=4 R_{C}^{2}\left[\gamma_{C}^{(1)}\right]^{2}
$$

Підставляючи формули (3) i (4) в (10), 3 урахуванням позначень (11) i (12), отримаємо формули для $K\left\lfloor\alpha_{y T}^{(1)}\right\rfloor$ у вигляді залежності від $\sigma^{2}\left(R_{y 1}^{(2)}\right)$ i $\sigma^{2}\left(R_{y 2}^{(2)}\right)$ :

$K\left[\alpha_{y T}^{(1)}\right]=\frac{p_{1} p_{2}+A p_{02} p_{2}+B p_{02} p_{1}}{p_{1} p_{2}+A p_{01} p_{2}+B p_{01} p_{1}} \times \frac{p_{1}+D p_{01}}{p_{1}+D p_{02}}$,

де $p_{01}, p_{02}$ визначаються (6) при підстановці

$$
\begin{aligned}
& \sigma^{2}\left(R_{y 1}^{(2)}\right) \text { i } \sigma^{2}\left(R_{y 2}^{(2)}\right) ; \\
& D=A, \text { якщо } \alpha_{y T}^{(1)}=\gamma_{y T}^{(1)} ; \\
& D=B, \text { якщо } \alpha_{y T}^{(1)}=\varepsilon_{y T}^{(1)} .
\end{aligned}
$$

Відповідно до (13) вплив $\sigma^{2}\left(R_{y}^{(2)}\right)$ на $K\left[\alpha_{y T}^{(1)}\right]$ здійснюється непрямо параметром $p_{0}$. Проаналізуємо його структуру. В роботі [1] показано, що при існуючому рівні апаратурних складових похибок АЦСКО і відношенні сигнал/шум $q_{0}^{2}=100$ дисперсія оцінки радіального прискорення в режимі ФТН-16 складає біля $1 \mathrm{~m}^{2} / \mathrm{c}^{4}$. При значеннях середньоквадратичного відхилення оцінки кутомісної швидкості за результатами поточної обробки $60^{\prime} . .100^{\prime}$, що характерно для РЛС НГВ, другий доданок в (6) складає $(2,9 . .8,2) \times 10^{-2} \mathrm{~m}^{2} / \mathrm{c}^{4}$. Тому у першому наближенні цим доданком в (6) нехтуємо та далі вважаємо

$$
p_{0} \cong \sigma^{-2}\left[R_{y}^{(2)}\right\rfloor \text {. }
$$

3 врахуванням (14) формула (13) запишеться у виді:

$K\left[\alpha_{y T}^{(1)}\right]=\frac{p_{1} p_{2} \sigma^{2}\left[R_{{ }^{2}}^{(2)}\right]+A p_{2}+B p_{1}}{p_{1} p_{2} \sigma^{2}\left[R_{y 1}^{(2)}\right]+A p_{2}+B p_{1}} \cdot \frac{p_{1} \sigma^{2}\left[R_{y 1}^{(2)}\right]+D}{p_{1} \sigma^{2}\left[R_{V_{2}}^{(2)}\right]+D}$.

Результати порівняльної оцінки точнісних характеристик алгоритмів уточнення кутових швидкостей балістичних і космічних об'сктів. Порівняльну оцінку проведемо для двох крайніх випадків:

випадок 1 - ціль атакуюча (точка дислокації РЛС належить площині орбіти/стрільбі БКО);

випадок 2 - ціль пролітаюча (площина орбіти/стрільби перпендикулярна вертикальній площині, що проходить через нормаль до апертури антени РЛС).

Випадок 1. У випадку атакуючої цілі $\varepsilon_{C}^{(1)} \approx 0,\left|\gamma_{C}^{(1)}\right|>0$. Базуючись на (11) $A \approx 0$ та формула (15) з врахуванням (9) для кутомісної швидкості зводиться до виду

$$
\left.K_{A}\left[\gamma_{y T}^{(1)}\right] \approx \frac{\left.B+p_{2} \sigma^{2} \mid R_{y 2}^{(2)}\right]}{B+p_{2} \sigma_{2}\left[R_{y 1}^{(2)}\right.}\right] d .
$$

Припустимо спочатку, що систематичні похибки при оцінюванні нехтувано малі:

$$
\sigma^{2}\left(\Delta \gamma^{(1)}\right)<\sigma^{2}\left(\gamma_{C}^{(1)}\right) \text {. }
$$

Тоді згідно (8) $p_{2}$ досягає свого максимального значення $p_{2}=p_{2 \max }=\sigma^{-2}\left(\gamma_{C}^{(1)}\right)$ та

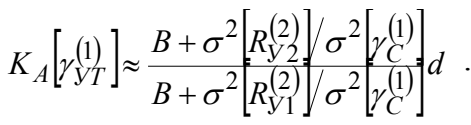

Оскільки при існуючому рівні точності оцінювання $R_{C}$ і $R_{y}$ нерівність

$$
B=4 R_{C}^{2}\left[\gamma_{C}^{(1)}\right]^{2}>>\sigma^{2}\left\lfloor R_{y}^{(2)}\right] / \sigma^{2}\left\lfloor\gamma_{c}^{(1)}\right\rfloor
$$

справедлива у межах всієї зони огляду РЛС НГВ, остаточно отримаємо

$$
\left.K_{A} \mid \gamma_{y T}^{(1)}\right] \approx d .
$$

Діючи аналогічно, у випадку азимутальної швидкості отримаємо

$$
K_{A}\left\lfloor\varepsilon_{y T}^{(1)}\right\rfloor \approx 1,
$$

тобто точність оцінки азимутальної швидкості атакуючої цілі не залежить від точності оцінки $R_{y}^{(2)}$.

Відмова від припущення (17) означає зменшення $p_{2}$ відносно його максимального значення, що додатково зменшуе вклад оцінки $R_{y}^{(2)}$ у дріб (18) і тільки підвищує точність оцінки (20).

Випадок 2. У випадку пролітаючої цілі $\gamma_{C}^{(1)} \approx 0,\left|\varepsilon_{C}^{(1)}\right|>0$. Базуючись на (12), маємо $B \cong 0$ і формула (15) з врахуванням (9) для азимутальної швидкості перетворюється до виду

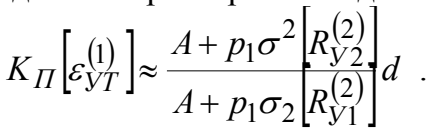

Коли систематичні похибки при оцінюванні $\varepsilon_{C}^{(1)}$ нехтувано малі $\sigma^{2}\left(\Delta \gamma^{(1)}\right)<<\sigma^{2}\left(\gamma_{C}^{(1)}\right)$, значення параметра $p_{1}$ досягають свого максимума $p_{1}=p_{1 \max }=\sigma^{-2}\left(\varepsilon_{C}^{(1)}\right)$. При цьому формула (22) трансформується та має вид

$$
\left.K_{\Pi}\left[\varepsilon_{y T}^{(1)}\right] \approx \frac{A+\sigma^{2}\left[R_{y 2}^{(2)}\right]}{A+\sigma^{2}\left[R_{y 1}^{(2)}\right.}\right] / \sigma^{2}\left[\begin{array}{l}
\sigma^{2}\left[\varepsilon_{C}^{(1)}\right. \\
\varepsilon_{C}^{(1)}
\end{array}\right] d .
$$

За існуючої точності оцінювання $\vec{R}_{C}$ і $\vec{R}_{y}$ нерівність $\quad A=4 R_{C}^{2}\left[\varepsilon_{C}^{(1)}\right]^{2} \gg \sigma^{2}\left[R_{y}^{(2)}\right] / \sigma^{2}\left[\varepsilon_{c}^{(1)}\right]$ справедлива в межах всієї зони виявлення РЛС НГВ. Тому для азимутальної швидкості остаточно отримаємо

$$
K_{\Pi}\left[\varepsilon_{y T}^{(1)}\right] \approx d .
$$

Наявність систематичних похибок призводить до зменшення $p_{1}$ відносно свого максимального значення $p_{1 \max }$. Це означає зменшення вкладу оцінки $R_{y}^{(2)}$ у дріб (23), що приводить до підвищення точності оцінки (24).

Для кутомісної швидкості після аналогічних 
процедур маємо

$$
K_{\Pi}\left[\gamma_{\text {уT }}^{(1)}\right] \approx 1 \text {. }
$$

Бачимо, що у випадку пролітаючої цілі від точності оцінки $R_{y}^{(2)}$ не залежить точність оцінки кутомісної швидкості.

Таким чином, за допомогою розробленої методики встановлено, що підвищення точності оцінки за даними АУВПД безпосередньо перераховується у підвищення точностей оцінок кутомісної швидкості атакуючої та азимутальної швидкості пролітаючої цілі. При оцінці значень параметра $d$ необхідно враховувати той факт, що він залежить від кількості $M$ опорних точок (результатів вимірювань АЦСКО), які пройшли селекцію в АТО. Число ОТ, що пройшли селекцію, може варіюватись від $N_{\min }=5$ до $N_{\max }=$ 18 [2]. Тому замість $d$ треба користуватись його середнім значенням

$$
\xi_{2}(v ; M)=(1 / k(M)) \sum_{n=1}^{k(M)} \xi_{2}(v ; M, n),
$$

де $\xi_{2}(v, M, n)=\sigma^{2}\left(R_{y_{v}}^{(2)}, M, n\right) \sigma^{2}\left(R_{y_{0}}^{(2)}, M, n\right)$ - відношення дисперсій, коли в якості першої оцінки використовується $v$-й варіант побудови АУВПД, а у якості другого варіант $\boldsymbol{v}=0$,

$$
\begin{aligned}
& k(M)=C_{N_{O T}-N_{\min }}^{M-N_{\min }}= \\
& =\left(N_{O T}-N_{\min }\right) !\left(M-N_{\min }\right) !\left(N_{O T}-M\right) !
\end{aligned}
$$

визначає кількість переборів варіантів розміщення $M$ OT. Варіант $v=0$ самий простий. Він передбачає вимірювання тільки радіальних швидкостей в режимі С8 та в трьох точках ФТН-16. Варіант $v=1$ відповідає штатному режиму: вимірюються радіальні швидкості в режимі С8 та радіальні швидкості і прискорення в трьох точках ФТН-16. На рис. 1 зображені графіки середнього виграшу в точності оцінки радіального прискорення відносно самого простого $(v=0)$ для різних варіантів побудови $v=\overline{1,10}$ АУВПД в залежності від числа $M$ опорних точок.

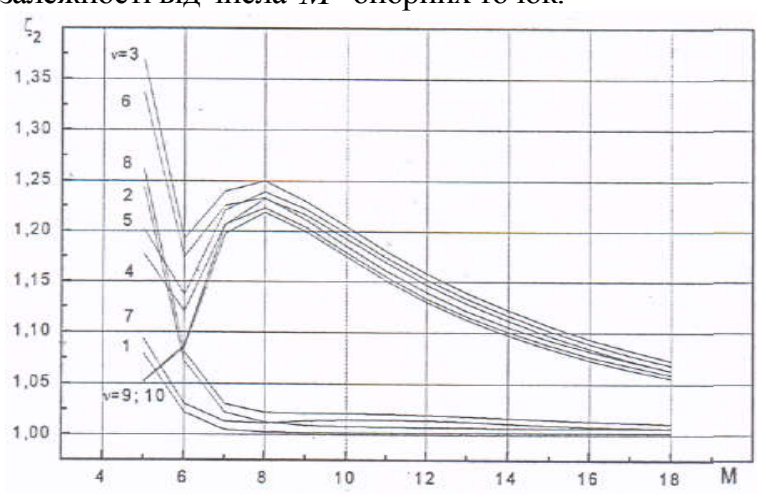

Рис. 1. Середній виграш у точності оцінки радіального прискорення

Детальна характеристика цих варіантів дана в табл. 2 роботи [6]. Аналіз графіків показав, що при кількості ОТ, які пройшли селекцію, $\mathrm{M}=5$ середній виграш порівняно із штатним варіантом складає для компромісно-оптимальних варіантів: $v=2$ біля 13\%, $v$ $=6$ біля $26 \%, v=3$ біля $30 \%$. У випадку, коли $M=10$, маємо $0,5 \%, 14 \%, 16 \%$, а при $M=15$ - біля $0,5 \%, 9 \%$, $11 \%$ відповідно.

Максимальне значення виграшу при $M>6$ спостерігається для варіантів $\nu=6$ і 3 при $M=8$ та складає біля $24 \%$ и $25 \%$ відповідно. Наявність максимума залежності $\xi_{2}(v ; M)$ та його положення, що відповідає $M=8$, пояснюється залежністю від концентрації числа розміщень ОТ, які містять наступні високоточні вимірювання (i вимірювання $R^{(2)}$ у тому числі), тобто другу та третю ОТ режиму

ФТН. При довільній орієнтації площини стрільби/орбіти цілі відносно РЛС підвищення точності оцінки радіального прискорення приводить до підвищення точності обох кутових швидкостей цілі у відповідності до формули (15).

3. Аналіз впливу врахування третьої похідної дальності на точність оцінки кутомісної швидкості пролітаючої цілі. Згідно (25) кутомісна швидкість $\gamma_{C}^{(1)}$ пролітаючої цілі не уточнюється оцінками $R_{y}^{(2)}$. Однак, існує принципіальна можливість іiі уточнення за рахунок залучення інформації про третю похідну дальності, яка отримана АУВПД в режимі ФТН-32. При цьому виграш в точності оцінки, як і раніше, будемо характеризувати відносним показником

$$
K_{3}\left\lfloor\gamma_{y T}^{(1)}\right\rfloor=\sigma^{2}\left\lfloor\gamma_{y T 1}^{(1)}\right\rfloor / \sigma^{2}\left\lfloor\gamma_{Y T 3}^{(1)}\right\rfloor,
$$

де $\gamma_{y T 1}^{(1)}, \gamma_{\text {УT3 }}^{(1)}$ - оцінки, отримані із залученням інформації про $R_{y}^{(2)}$ та про третю похідну квадрату дальності $\varsigma^{(3)}$ (тут i далі позначено $\varsigma=R^{2}$ ) відповідно.

Можна показати, що

$$
\begin{aligned}
& K_{3}\left[\gamma_{y T}^{(1)}\right]=1+ \\
& +G_{1}^{2} \sigma^{2}\left[\gamma_{C}^{(1)}\right]\left\{\sigma^{2}\left[\varsigma_{0}^{(3)}\right]+G_{0}^{2} \sigma^{2}\left(\gamma_{C}\right)\right\},
\end{aligned}
$$

де $G_{0}=\partial \varsigma_{0}^{(3)} / \partial \gamma ; \quad G_{1}=\partial \varsigma_{0}^{(3)} / \partial \gamma^{(1)} ; \varsigma_{0}^{(3)}$ оцінка $\varsigma^{(3)}$ на середину інтервалу згладжування.

Величину $\varsigma^{(3)}$ визначаємо шляхом послідовного диференціювання за часом квадрата дальності $\varsigma=R^{2}(t)=\left[\sum_{k=0}^{3} R^{(k)}(\Delta t)^{k} / k !\right]^{2}\left(\Delta t=t-t_{0}, t_{0}\right.$ - центр інтервалу згладжування) як функції часу та оцінок радіальних параметрів $\left\{R^{(k)}, k=\overline{0,3}\right\}$ за даними АУВПД. Отримаємо

$$
\begin{aligned}
& \varsigma^{(3)}=6\left(R R^{(3)} / 3+R^{(1)} R^{(2)}\right)+ \\
& \quad+24\left[R^{(1)} R^{(3)} / 3-\left[R^{(2)}\right]^{2} / 4\right] \Delta t+ \\
& +(5 / 72) R^{(2)} R^{(3)}(\Delta t)^{2}+(1 / 120)\left[R^{(3)}\right]^{2}(\Delta t)^{3} .
\end{aligned}
$$

При цьому оцінка $\varsigma^{(3)}$ на середину інтервалу згладжування визначається як

$$
\varsigma_{0}^{(3)}=6\left(R R^{(3)} / 3+R^{(1)} R^{(2)}\right),
$$

а дисперсія оцінки $\varsigma_{0}^{(3)}$ визначається повним диференціалом формули (31) як функції радіальних параметрів руху цілі. 3 врахуванням КМП вектора оцінок радіальних параметрів по даним АТО $K_{\text {AтO }}=\left\|K\left(R^{(k)}, R^{(n)}\right)\right\|=\left\|K_{k, n}\right\| ; k, n=\overline{0,3}$ вона має вид 


$$
\begin{aligned}
& \sigma^{2}\left[\varsigma_{0}^{(3)}\right]=4\left[R^{(3)}\right]^{2} \sigma_{0}^{2}+36\left[R^{(2)}\right]^{2} \sigma_{1}^{2}+ \\
& +36\left[R^{(1)}\right]^{2} \sigma_{2}^{2}+4 R^{2} \sigma_{3}^{2}+8 R R^{(3)} K_{0,3}+ \\
& +24 R^{(2)} R^{(3)} K_{0,1}+24 R^{(1)} R^{(3)} K_{0,2}+24 R R^{(2)} K_{1,3}+ \\
& +24 R R^{(1)} K_{2,3}+72 R^{(1)} R^{(2)} K_{1,2} .
\end{aligned}
$$

Визначення $G_{0}$ та $G_{1}$ у Формулі (29) базується на залежності від кутових параметрів цілі, що отримується трикратним диференціюванням за часом співвідношення

$\varsigma=R^{2}(t)=r^{2}-R_{3}^{2}-2 R_{3} R \sin \gamma \sin \varepsilon$,

де $r$ радіус-вектор БКО як складної функції $R(t), \gamma(t), \varepsilon(t)$. Виконаний на основі (29)..(33) аналіз показав, що в умовах функціонування РЛС НГВ за будь-якого варіанту, що розглянуті в [4], має місце нерівність $\sigma^{2}\left[\varsigma_{0}^{(3)}\right]<<G_{0}^{2} \sigma^{2}\left[\gamma_{C}\right]$, тобто

$$
K\left[\gamma_{y T}^{(1)}\right]=1+\frac{G_{1}^{2} \sigma^{2}\left[\gamma_{C}^{(1)}\right]}{G_{0}^{2} \sigma^{2}\left[\gamma_{C}\right]} \approx \operatorname{const}\left\{\sigma^{2}\left[\varepsilon_{0}^{(3)}\right]\right\} .
$$

Результати розрахунків $K\left[\gamma_{y T}^{(1)}\right]$ для сімейства цілей 3 траєкторіями, які близькі до пролітаючих, наведено на рис. 2 у виді залежностей від $\left|R^{(1)}\right|$ при piзних $R^{(2)}$. Криві на рис. 2 показують, що виграш в точності порівняно зі штатною оцінкою $\gamma^{(1)}$ досягає $2 . .5$ раз по дисперсії при $\left|R^{(2)}\right| \in[20 ; 150] \quad \mathrm{Mc}^{2}$ і $\left|R^{(1)}\right| \in[0 ; 100]$ м / с. Таким чином, підтверджена дієвість уточнення оцінки $\gamma_{C}^{(1)}$ в умовах функціонування РЛС НГВ за рахунок використання результатів вимірювання третьої похідної дальності $\widehat{R}^{(3)}$ за даними режиму ФТН-32. Відповідно, реалізацію режиму ФТН-32 доцільно включити в перелік доробок комплексного робочого алгоритму РЛС НГВ.

\section{Jimepamypa}

1. Андреев Ф. М. Оценка точности измерения радиальных скорости и ускорения цели по данным системы когерентной обработки РЛС / Ф. М. Андреев, А. В. Статкус // Системы управления, навигации та зв'язку, 2012. - вип. 4 (24). - С. 17-24. 2. Изделие 5H86. Рабочий алгоритм и программа. Техническое описании алгоритма 4П-00-00-00. Часть I. 1985. - 243 с. 3. Саврасов Ю. С. Алгоритмы и программы в радиолокации / Ю. С. Саврасов. - М.: Радио и связь. - 1985. 216c. 4. Андреев Ф. М. Оценка ошибок измерения радиальных скорости и ускорения цели по данным моделирования / Ф. М. Андреев, А. В. Статкус // Вісник Харківського національного університету. Серія:

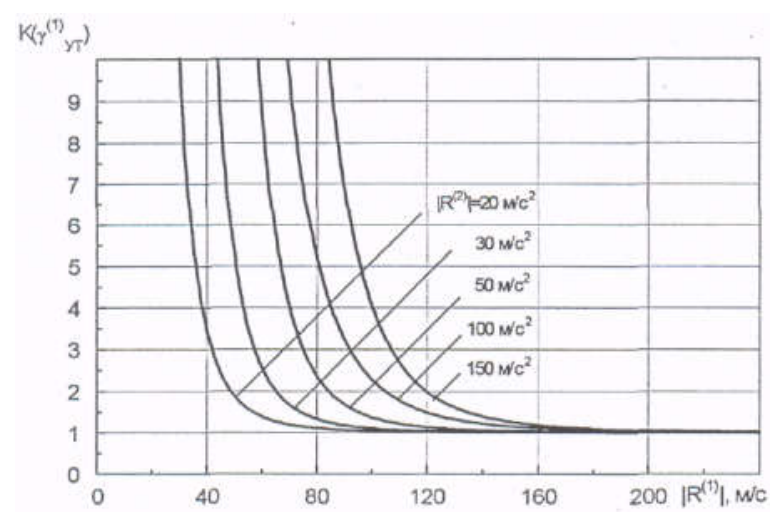

Рис. 2. середнього виграшу в точності оцінки радіального прискорення

\section{Висновки і перспективи подальших досліджень}

Розроблена методика порівняльної оцінки точнісних характеристик алгоритмів уточнення кутових швидкостей балістичних i космічних об'єктів РЛС НГВ. 3 їі допомогою встановлено, що за рахунок підвищення точності оцінки радіального прискорення, що досягається в результаті доробки алгоритма когерентної обробки та алгоритма уточнення вищих похідних дальності, забезпечується підвищення точності оцінки кутомісної швидкості атакуючої цілі та азимутальної швидкості пролітаючої цілі до 24\%..30\%. Введення режиму фазотраєкторного накопичення ФТН-32, коли цілі опромінюються пачкою із 32 імпульсів, дозволяє проводити додатково вимірювання третьої похідної дальності. Їх використання для оцінки уточнення кутомісної швидкості пролітаючих цілей дозволяє забезпечити виграш у порівнянні зі штатною оцінкою кутомісної швидкості до $2 . .5$ раз по дисперсії при $\left|R^{(2)}\right| \in[20 ; 150] \mathrm{Mc}^{2} \quad$ та $\left|R^{(1)}\right| \in[0 ; 100] \mathrm{M} / \mathrm{c}$.

«Математичне моделювання, інформаційні технології. Автоматизовані системи управління» - Харків: ХНУ, 2013. - вип. 1086. - С.47-52. 5. Статкус А.В. Совместное минимаксное оценивание трех первых производных дальности для системы когерентной обработки РЛС / А. В. Статкус, Ф. М. Андреев // Системи обробки інформації. - Харків: ХУПС, 2013. - вип. 9 (11) . - С. 78-84. 6. Андрєєв Ф. М. Вибір варіанту побудови алгоритму уточнення вищих похідних дальності до балістичних і космічних об'єктів / Андрєєв Ф. М., Статкус А. В., Ковбасюк С. В. // Сучасні інформаційні технології у сфері безпеки та оборони. - К. : НУОУ, 2017. - № 1(28). - С. 5 - 12.

\title{
ОЦЕНКА ВОЗМОЖНОСТИ УЛУЧШЕНИЯ ТОЧНОСТНЫХ ХАРАКТЕРИСТИК АЛГОРИТМОВ УТОЧНЕНИЯ УГЛОВЫХ СКОРОСТЕЙ БАЛЛИСТИЧЕСКИХ И КОСМИЧЕСКИХ ОБЪЕКТОВ В РЛС НАДГОРИЗОНТНОГО ОБНАРУЖЕНИЯ
}

\footnotetext{
${ }^{1}$ Сергей Валентинович Ковбасюк (доктор технических наук, с.н.с.)

${ }^{2}$ Феликс Михайлович Андреев (доктор технических наук, профессор)

${ }^{3}$ Андрей Витальевич Статкус (кандидат технических наук, доцент)
}

\author{
${ }^{1}$ Житомирский военный институт им. С. П. Королева, Житомир, Украина
}




\title{
${ }^{2}$ Харьковский Национальный университет им. В. Н. Каразина, Харьков, Украина \\ ${ }^{3}$ Харьковский Национальный технический университет, Харьков, Украина
}

В предылуших работах авторами рассмотрены теоретические возможности и практические рекомендации повышения точности определения координат и достоверности классификачии баллистических и космических объектов за счет определения высиих производньих дальности до объекта наблюдения $в$ радиолокаиионных станциях надгоризонтного обнаружения. Однако авторами не были рассмотрены рекомендачии по практическому выбору варианта построения алгоритма уточнения угловых скоростей, который обеспечивает максимальную точность оценивания координат иели. Поэтому в статье рассмотрена методика сравнительной оценки точностных характеристик алгоритмов уточнения угловых скоростей баллистических и космических объектов и оценки уровня их улучшения за счет использования разных вариантов построения алгоритма уточнения высших производных дальности, включая информаџию о третьей производной дальности. По результатам моделирования сформулированы выводы о выборе наилучшего варианта обработки данных в зависимости от обстановки и входных данных.

Ключевые слова: радиолокационные станции надгоризонтного обнаружения, баллистические и космические объекты, алгоритм уточнения угловых скоростей цели

\section{EVALUATION OF POSSIBILITIES TO IMPROVE ACCURACY CHARACTERISTICS FOR ALGORITHMS OF REFINEMENT ANGULAR VELOCITY OF BALLISTIC AND SPACE OBJECTS IN EARLY WARNING RADARS}

\author{
${ }^{1}$ Sergei V. Kovbasjuk (Doctor of Technical Science, Senior researcher) \\ ${ }^{2}$ Felix M. Andreev (Doctor of Technical Science, Professor) \\ ${ }^{3}$ Andrei V. Statkus (PhD in Radar and Wireless Systems, Associate professor) \\ ${ }^{\text {I} S . ~ P . ~ K o r o l e v ~ Z h i t o m i r ~ M i l i t a r y ~ I n s t i t u t e, ~ Z h i t o m i r, ~ U k r a i n e ~}$ \\ ${ }^{2}$ V. N. Karazin Kharkov National University, Kharkov, Ukraine \\ ${ }^{3}$ Kharkov National Technical University, Kharkov, Ukraine
}

The theoretical capabilities and practical recommendations of increasing the both an accuracy of coordinate estimation and reliability of ballistic and space targets classification by using estimates of range higher order derivatives for surveillance object in early warning radars (EWR) were studied in previous papers of the authors. Nevertheless, the recommendations were not considered as to practical design selection for the algorithm of refinement angular velocity of targets under the criterion of maximum accuracy of target coordinates estimation. Therefore, the article deals with the methodology of comparative evaluation accuracy characteristics of algorithms of refinement angular velocity ballistic and space objects and assessing the level of their improvement through the use of different variants of construction algorithm of increasing the accuracy of range higher order derivatives, including information on the third derivative of distance. By the results of modeling conclusions about choosing the best options for handling data depending on the context and the input

Key words: early warning radar, EWR, ballistic and space objects, algorithm of refinement angular velocity of targets

\section{Reference}

1. Andreev F. M. Evaluation of measurement accuracy in Doppler and range acceleration for radar coherent processing system [Otsenra tochnosti izmierieniia radialnykh skorosti $i$ uskorieniia tseli po dannym sistiemy obrabotki RLS] / F. M. Andreev, A. V. Statkus // Control, navigation and communication systems, 2012. - No. 4 (24). - PP. 17-24. 2. Item 5 N86. Operational algorithm and programme. Technical specification 4P-00-00-00. Part I [Rabochii algoritm $i$ programma. Tiekhnichieskoie opisaniie algoritma 4P-00-00-00. Chast I]. 1985. - 243 p. 3. Savrasov Yu. S. Algorithms and programs in radar [Algoritmy i programmy v radiolokattsii] / Yu. S. Savrasov. - Moscow: Radio and communications. - 1985. - 216 p. 4. Andreev F. M. Evaluation of measurement accuracy in Doppler and range acceleration using simulation [Otsenka oshibok izmierieniia radialnykh skorosti $i$ uskorieniia tseli po dannym modelirovaniia] / F. M. Andreev, A. V. Statkus // Kharkov National University Bulletin. Section "Mathematical
Modeling. Information Technologies. Automated Control Systems". - Kharkov: Kharkov National University, 2013. No. 1086. - PP.47-52. 5. Statkus A. V. Simultaneous minimax MSE estimation of three first range derivatives for radar coherent processing system [Sovmiestnoie minimaksnoie otsenivaniie triokh piervykh proizvodnykh dalnosti dlia sistemy kogierientnoi obrabotki RLS] / A. V. Statkus, F. M. Andreev // Information Processing Systems. - 2013. - No. 9 (11). - PP. 78-84. 6. Andreev F. M. Design substantiation for the algorithm of increasing the accuracy of range higher order derivatives for ballistic and space targets [Vybir varianta pobudovy algorytma utochnennia vyshchykh pokhidnykh dalnosti do balistychnykh $i$ kosmichnykh obiektiv] / F. M. Andreev, A. V.Statkus, S. V. Kovbasiuk // Modern Information Technology in the Sphere of Security and Defence. - Kyiv : NDUU, 2017. - № 1(28). - PP. $5-12$. 